\title{
A Primary Exploration of Variety Selection and Efficient Cultivation Models for Cassava/Peanut Intercropping
}

\author{
Xiumei Tang ${ }^{1,2}$, Ruichun Zhong ${ }^{1}$, Jing Jiang ${ }^{1}$, Liangqiong $\mathrm{He}^{1}$, Faqian Xiong ${ }^{1}$, Zhipeng Huang ${ }^{1}$, \\ Haining $\mathrm{Wu}^{1}$, Jing Liu ${ }^{1}$, Longfei $\mathrm{He}^{2}$, Ronghua Tang ${ }^{1, *}$ \\ ${ }^{1}$ Cash Crops Research Institute, Guangxi Academy of Agricultural Sciences, Nanning, China \\ ${ }^{2}$ Agricultural College of Guangxi University, Nanning, China
}

Email address:

tangxiumei2005@163.com (Xiumei Tang), tronghua $a$ 163.com (Ronghua Tang)

${ }^{*}$ Corresponding author

\section{To cite this article:}

Xiumei Tang, Ruichun Zhong, Jing Jiang, Liangqiong He, Faqian Xiong, Zhipeng Huang, Haining Wu, Jing Liu, Longfei He, Ronghua Tang. A Primary Exploration of Variety Selection and Efficient Cultivation Models for Cassava/Peanut Intercropping. International Journal of Applied Agricultural Sciences. Vol. 4, No. 3, 2018, pp. 86-92. doi: 10.11648/j.ijaas.20180403.15

Received: August 16, 2018; Accepted: September 3, 2018; Published: September 30, 2018

\begin{abstract}
In this study, we determined the agronomic traits and yields of peanuts under different intercropping models by carrying out tests on variety selection, row spacing, and film mulching during sowing of intercropped peanuts. We analyzed the high-yield and comprehensive benefits in order to determine the efficient cultivation models of cassava/peanut intercropping. The results showed that among the eight tested peanut varieties, Guihua771 was the most suitable for intercropping with cassava, and its yield was $18.7 \%$ higher than Guihua17 - the local control variety - followed by Guihua22 and Guihua836. In the intercropping model selection test, the yield income of one row of cassava, intercropped with two rows of peanuts, under medium-narrow spacing $(0.9-1.1 \mathrm{~m})$ was significantly higher than that of one row of cassava intercropped with three or four rows of peanuts with wide spacing $(1.3-1.4 \mathrm{~m})$. The income of intercropped peanuts with film mulching was higher than that without the film, and the income from cassava and peanut intercropping $15 \mathrm{~d}$ apart was higher than that of planting the cassava and peanuts at the same time. The best overall yield income was obtained when using Guihua771 as the peanut variety, intercropped with cassava using a row spacing arrangement of one row of cassava with two rows of peanuts, and planting the peanuts $15 \mathrm{~d}$ ahead of the cassava, with mulching film.
\end{abstract}

Keywords: Cassava, Peanuts, Intercropping, Variety Selection, Cultivation Model

\section{Introduction}

Cassava is mainly planted in south China, with the largest planting area in Guangxi, occupying $60 \%$ of China's cassava planting area. However, cassava monoculture has a long growth period (10-11 months), slow growth in the early phase, a late closing period (4-5 months), sparse planting (row spacing 1-1.5m) and low utilization of land and light energy, resulting in low yield per unit of cultivated land area, and low economic benefit. The peanut plant is short, with a short growth period (about 4 months) and narrow row spacing $(0.4$ $\mathrm{m})$, thus forming complementary "long-short," "high-low," and "wide-narrow" effects with cassava in the ecological niches of time, space, and nutrition. Intercropping these two plants can effectively integrate land, light, and heat resources, making intensive use of time and space to maximize economic and ecological benefits, increase yield and income, and improve land utilization and maintenance. Therefore, cassava/peanut intercropping is of great significance for full utilization of limited cultivated land resources in south China. It can also help solve the contradiction in land use between cash and food crops. Some studies have been done on intercropping techniques between cassava rows, and the theoretical basis thereof. Benhui Wei et al. [1] and Zhanqi Yuan et al. [2] showed that intercropping cassava with watermelon, winter gourd, muskmelon, peanuts, and green soy beans increased the yield and income per unit of cultivated land. Xinglu Luo [3] and Qianru Huang et al. [4] studied the yield effect and eco-economic benefit of intercropping cassava and peanuts. International studies on cassava/peanut 
intercropping have been carried out for many years. As early as 1986, Mason [5-7] studied the agronomic characteristics and yield benefit of cassava/peanut intercropping and soil nutrient transformation efficiency. Polthanee [8-9] and Kotchasatit [10] also conducted similar studies on cassava/peanut intercropping from 1998-1999. For the past few years, some scholars reseaeched the eco-physiological mechanisms of cassava/peanut intercropping, such as microecology in rhizosphere soil [11-12], physical and chemical properties [13], carbon-nitrogen metabolism[14], absorption of cadmium and available nutrient[15]. The above studies mainly focus on the agronomic traits, yield benefit analysis and mechanisms under intercropping cultivation, but there is still lack of a comprehensive and systematic discussion on efficient cassava/peanut intercropping cultivation models. Therefore, this paper sorts through peanut varieties suitable for intercropping with cassava, analyzes the arrangement of row spacing, and tests film mulching and sowing time gaps. Doing so will preliminarily identify the best cultivation model, and provide technical reference to further optimize cassava/peanut intercropping yield and planting.

\section{Materials and Methods}

\subsection{Test Materials}

The tested peanut varieties were Guihuahong166, Guihua17, Guihua22, Guihua26, Guihua30, Guihua771, Guihua836 and Guihua1026. Guihuahong166, Guihua17, Guihua22, Guihua26 and Guihua 30 are all local conventional cultivar in Guangxi, and Guihua771, Guihua836 and Guihua 1026 were newly bred peanut varieties in recent years. All these varieties were provided by the Cash Crops Research Institute, Guangxi Academy of Agricultural Sciences. Huanan205, the main cultivar in Guangxi, provided by farmers in Wuming County, Guangxi Province, was selected as the cassava variety in these tests.

\subsection{Test Design}

The tests were carried out at the Wuming Lijian Research Base of the Guangxi Academy of Agricultural Sciences. Based on the cassava/peanut intercropping model commonly adopted by local farmers, selection tests on the varieties of peanuts suitable for intercropping were carried out from 2010-2012. One row of cassava was intercropped with two rows of peanuts on flat land, with the row spacing between cassava rows being $1.1 \mathrm{~m} \times 0.8 \mathrm{~m}$, the row spacing between cassava and peanuts as $0.4 \mathrm{~m}$, and the row spacing between peanuts as $0.3 \mathrm{~m} \times 0.16 \mathrm{~m}$. A total of eight peanut varieties were tested, with Guihua17, the widely used peanut variety in a large area of Guangxi, as the control. The intercropping cultivation model selection tests were carried out from 2013-2015. A total of three models were tested for row spacing arrangement: 0.9 (2) indicates one row of cassava intercropped with two rows of peanuts, with a row spacing of $0.9 \mathrm{~m} ; 1.1$ (2) indicates one row of cassava intercropped with two rows of peanuts at a spacing of $1.1 \mathrm{~m} ; 1.3$ (3) indicates one row of cassava intercropped with three rows of peanuts, with a row spacing of $1.3 \mathrm{~m}$; and 1.5 (4) indicates one row of cassava intercropped with four rows of peanuts, at a row spacing of $1.5 \mathrm{~m}$. A total of four models were tested for film mulching during sowing: cassava and peanut were planted at the same time (time gap of $0 \mathrm{~d}$ ), peanuts were planted $15 \mathrm{~d}$ ahead of cassava (time gap of $15 \mathrm{~d}$ ), cassava and peanuts were intercropped at the same time and covered with mulching film $(\mathrm{m} 0 \mathrm{~d})$, and cassava and peanuts were planted with a time gap of $15 \mathrm{~d}$ and covered with mulching film (m $15 \mathrm{~d}$ ). For all models, three duplicates were processed with randomized block design, and the block area was $28.8 \mathrm{~m}^{2}$.

\subsection{Sampling Determination}

Mature peanut plants were analyzed in each block at harvest to investigate plant and pod traits. The harvested peanuts were measured to determine block yield after being naturally dried and after the sediments and plant residues were removed, and they were converted to yield per hectare. After cassava were harvested, the yield of their seeds was measured and converted to yield per hectare, and the economic benefit of intercropping was calculated at current market prices, together with the yield of the harvested peanuts.

\subsection{Data Analysis}

Excel 2007 was used for data analysis and for drawing the three-line tables. All data in the tables are the average of the three series.

\section{Results and Analysis}

\subsection{Investigation on Traits of Different Intercropped Peanut Varieties}

As shown in Table 1, the growth of different peanut varieties under cassava/peanut intercropping models differed. The order of the main stem heights was as follows: Guihua $22>$ Guihua $1026>$ Guihua17 > Guihua30 > Guihua771 > Guihua836 > Guihua26 > Guihuahong166. The main stem of Guihua22 was the highest, Guihuahong166 was the shortest, and Guihua771 was the median. The lateral branch length of Guihua22 was also the greatest, $32.2 \%$ greater than that of Guihua17, the control variety. The lateral branch of Guihua771 was the shortest. In addition, the total and effective numbers of branch of Guihua771 were the largest. The effective number of branch on Guihua771 was one greater than that of the other six peanut varieties. In contrast, the number of nodes on main stem of Guihua771 was the least, 1.3 less than that of the control variety, Guihua17. The stem diameter of Guihua 771 was the largest, $6.1 \%$ greater than that of the control variety, Guihua17, demonstrating that the growth of peanut plants under intercropping varies by variety, and the differences in main stem height and lateral branch length were significant. 
Table 1. Effects of cassava/peanut intercropping on the traits of different peanut varieties.

\begin{tabular}{lllllll}
\hline Peanut variety & $\begin{array}{l}\text { Height of main } \\
\text { stem } \mathbf{( c m )}\end{array}$ & $\begin{array}{l}\text { Length of lateral } \\
\text { branch } \mathbf{( c m )}\end{array}$ & $\begin{array}{l}\text { Total number of } \\
\text { branch (count) }\end{array}$ & $\begin{array}{l}\text { Number of effective } \\
\text { branch (count) }\end{array}$ & $\begin{array}{l}\text { Number of nodes on } \\
\text { main stem(count) }\end{array}$ & $\begin{array}{l}\text { Stem diameter } \\
\text { (mm) }\end{array}$ \\
\hline Guihua17 & 55.9 & 51.3 & 4.3 & 4.1 & 18.4 & 3.61 \\
Guihua22 & 66.4 & 67.8 & 4.4 & 4.4 & 18.2 & 3.28 \\
Guihua26 & 53.4 & 51.3 & 4.3 & 4.2 & 18.4 & 2.91 \\
Guihua30 & 53.50 & 56.4 & 4.6 & 4.3 & 18.8 & 2.89 \\
Guihua771 & 55.2 & 50.7 & 5.0 & 4.0 & 17.1 & 3.83 \\
Guihua836 & 54.0 & 51.9 & 4.2 & 4.5 & 17.9 & 3.36 \\
Guihua1026 & 56.2 & 53.3 & 4.5 & 4.4 & 17.9 & 3.47 \\
Guihuahong 166 & 42.98 & 45.93 & 4.5 & & & 3.66 \\
\hline
\end{tabular}

\subsection{Investigation on Pod Traits of Different Intercropped Peanut Varieties}

As shown in Table 2, when intercropped with cassava, the order of the numbers of mature pods per peanut plant is shown as follows: Guihua $22>$ Guihua $836>$ Guihua $771>$ Guihua Red $166>$ Guihua $26>$ Guihua $17>$ Guihua $30>$ Guihua 1026 . The number of mature pods on a single plant included single and double kernel pods, and the latter was the main factor affecting pod yield. However, Guihua 22 had the most single kernel pods, and Guihua 17 and Guihua 771 had the least single kernel pods; Guihua 771 and Guihua 836 had the largest number of double kernel pods, both $14.5 \%$ higher than the control variety Guihua 17 . The two were followed by Guihua 22. Guihua 17 and Guihua 22 had the most blighted pods, in the range of 3.1 to 4.6. The other tested peanut varieties had numbers in the range from 0.6 to 2.5 . The weight of a hundred pods, kernel yield, and single plant yield of Guihua 771 were the highest, at $21.9 \%, 4.8 \%$ and $114.9 \%$ higher than those of the control variety Guihua 17, respectively. The weights of a hundred kernels of Guihua 22 and Guihua 771 were $26.3 \%$ and $19.3 \%$ higher than the control variety, respectively, which may be related to the size of the pod kernel itself, and the pod plumpness under intercropping.

Table 2. Effects of cassava/peanut intercropping on pod traits of different peanut varieties.

\begin{tabular}{lllll}
\hline Peanut variety & $\begin{array}{l}\text { Number of mature pods on } \\
\text { single plant (count) }\end{array}$ & $\begin{array}{l}\text { Number of single kernel } \\
\text { pods (count) }\end{array}$ & $\begin{array}{l}\text { Number of double kernel } \\
\text { pods (count) }\end{array}$ & $\begin{array}{l}\text { Number of blighted pods } \\
\text { (count) }\end{array}$ \\
\hline Guihua17 (ck) & 11.4 & 1.7 & 9.7 & 11.0 \\
Guihua22 & 13.9 & 2.9 & 9.4 & 3.6 \\
Guihua26 & 11.6 & 2.2 & 8.8 & 0.6 \\
Guihua30 & 11.1 & 2.3 & 11.1 & 2.1 \\
Guihua771 & 13.0 & 1.9 & 11.1 & 1.1 \\
Guihua836 & 13.3 & 2.1 & 6.1 & 1.0 \\
Guihua1026 & 8.7 & 2.1 & 8.3 \\
Guihuahong 166 & 11.8 & 3.5 & & 2.5 \\
\hline
\end{tabular}

Table 2. Continued.

\begin{tabular}{|c|c|c|c|c|}
\hline Peanut variety & Weight of a hundred pods (g) & Weight of a hundred kernels(g) & Kernel rate (\%) & Single plant yield(g) \\
\hline Guihua17 (ck) & 146 & 57 & 69.0 & 9.4 \\
\hline Guihua22 & 173 & 72 & 71.1 & 20.2 \\
\hline Guihua26 & 174 & 65 & 66.4 & 14.2 \\
\hline Guihua30 & 158 & 66 & 65.1 & 12.78 \\
\hline Guihua771 & 178 & 68 & 72.3 & 20.3 \\
\hline Guihua836 & 175 & 62 & 65.1 & 16.0 \\
\hline Guihuahong 166 & 149 & 53 & 69.3 & 10.38 \\
\hline
\end{tabular}

\subsection{Comparison and Analysis of Yield of Different Intercropped Peanut Varieties}

As shown in Table 3, the yields of intercropped peanut varieties varied significantly. In the peanut variety intercropping selection test in 2010, the yield of Guihua771 was the highest $45.7 \%$ higher than that of the control variety - followed by Guihua22 and Guihua26. In the test in 2011, the yields of Guihua 22 and Guihua 771 were also the highest, at $16.5 \%$ and $10.6 \%$ higher than that of the control variety respectively. In the test in 2012, the yields of Guihua 836 and Guihua 771 were the highest:
$18.1 \%$ and $8.1 \%$ higher than that of the control variety respectively. The order of the average yield over the 3 years is shown as follows: Guihua771 > Guihua22 > Guihua836 > Guihua26 > Guihua17 > Guihua30 > Guihua1026 > Guihuahong166. The average yield of Guihua771 was the largest over the three years, $18.7 \%$ higher than that of the control variety Guihua 17. The results showed that the yield of Guihua771 was the most stable among the six tested varieties, suggesting that Guihua771 was most suitable for intercropping with cassava, followed by Guihua 22 and Guihua 836 . 
Table 3. Yield of intercropping between different peanut varieties and cassava.

\begin{tabular}{|c|c|c|c|c|}
\hline \multirow{2}{*}{ Peanut variety } & \multicolumn{3}{|c|}{ Yield of peanut being intercropped $\left(\mathrm{kg} / \mathrm{hm}^{2}\right)$} & \multirow[b]{2}{*}{ Average yield(kg/ hm } \\
\hline & 2010 & 2011 & 2012 & \\
\hline Guihua17 & 1453.7 & 2109.2 & 2121.3 & 1894.7 \\
\hline Guihua22 & 1999.8 & 2457.6 & 2227.4 & 2228.3 \\
\hline Guihua26 & 1954.7 & 2081.9 & 2163.8 & 2066.8 \\
\hline Guihua30 & 1367.9 & 1896.0 & 2329.4 & 1864.4 \\
\hline Guihua771 & 2117.3 & 2333.4 & 2294.1 & 2248.3 \\
\hline Guihua836 & 1943.4 & 2045.4 & 2506.2 & 2165.0 \\
\hline Guihua1026 & 1493.1 & 1954.5 & 1894.5 & 1780.7 \\
\hline Guihuahong166 & 1442.4 & 1936.7 & 1367.9 & 1582.3 \\
\hline
\end{tabular}

\subsection{Investigation on Peanut Plant Traits Under Different Intercropping Models}

As shown in Table 4, the main stem heights and lateral branch lengths of peanuts varied by intercropping model. The main stem height, lateral branch length, and stem diameter of intercropped peanuts with mulching film were higher than those without. The main stem heights of peanuts planted $15 \mathrm{~d}$ ahead of the cassava with mulching film were $11.9 \%$ taller than those of peanuts planted at the same time, without mulching film. The lateral branch length with mulching film was also $2-3 \mathrm{~cm}$ larger than without. In the case of no mulching, there was no significant difference in lateral branch lengths between planting with a gap of 15 days and at the same time. In addition, the total and effective number of branch, the number of nodes on the main stem, and the stem diameter of peanut plants with mulching film, planted with a gap of $15 \mathrm{~d}$, were all slightly higher than those figures without the film, planted at the same time.

In the tests on intercropping row spacing arrangements, the main stem height, lateral branch length, number of nodes on the main stem, and stem diameter of one row of cassava intercropped with three rows of peanuts with a medium-wide row spacing $(1.3 \mathrm{~m})$ were all larger than those figures with one row of cassava intercropped with two rows of peanuts with a narrow row spacing $(0.9 \mathrm{~m})$, and of one row of cassava intercropped with four rows of peanuts, with a wide row spacing $(1.5 \mathrm{~m})$. This result indicates that the main stem height of one row of cassava intercropped with three rows of peanuts with a wide row spacing $(1.3 \mathrm{~m})$ was $8.0 \%$ higher than that of one row of cassava intercropped with two rows of peanuts spaced at $0.9 \mathrm{~m}$, and $7.0 \%$ higher than that spaced at $1.1 \mathrm{~m}$. The number of effective branch was the highest with one row of cassava intercropped with two rows of peanuts, spaced at $1.1 \mathrm{~m}$.

Table 4. Effects of cassava/peanut intercropping model on peanut plant traits.

\begin{tabular}{lllll}
\hline Intercropping model & & Height of main stem (cm) & Length of lateral branch (cm) & Total number of branch (count) \\
\hline \multirow{3}{*}{ Sowing gap period (d) and } & $0 \mathrm{~d}$ & 56.8 & 55.0 & 4.4 \\
application of mulching film & $15 \mathrm{~d}$ & 55.0 & 54.6 & 4.1 \\
& $\mathrm{~m} \mathrm{0} \mathrm{d}$ & 58.1 & 57.0 & 5.0 \\
& $\mathrm{~m} \mathrm{15} \mathrm{d}$ & 63.6 & 56.7 & 4.9 \\
\multirow{2}{*}{ Row spacing of cassava (rows of } & $0.9(2)$ & 58.1 & 51.3 & 3.9 \\
peanut) & $1.1(2)$ & 58.6 & 49.7 & 4.2 \\
& $1.3(3)$ & 62.8 & 52.7 & 4.3 \\
\hline
\end{tabular}

Table 4. Continued.

\begin{tabular}{lllll}
\hline Intercropping model & & $\begin{array}{l}\text { Effective number of branch } \\
\text { (count) }\end{array}$ & $\begin{array}{l}\text { Number of nodes on main stem } \\
\text { (count) }\end{array}$ & Stem diameter (mm) \\
\hline & $0 \mathrm{~d}$ & 4.4 & 16.3 & 3.68 \\
Sowing gap period (d) and & $15 \mathrm{~d}$ & 4.1 & 17.1 & 3.72 \\
application of mulching film & $\mathrm{m} \mathrm{0} \mathrm{d}$ & 4.9 & 18.0 & 3.81 \\
& $\mathrm{~m} 15 \mathrm{~d}$ & 4.6 & 17.9 & 3.82 \\
& $0.9(2)$ & 3.9 & 17.1 & 3.69 \\
Row spacing of cassava (rows of & $1.1(2)$ & 4.2 & 16.3 & 3.73 \\
peanut) & $1.3(3)$ & 4.0 & 18.7 & 3.86 \\
& $1.5(4)$ & 4.0 & 17.8 & 3.65 \\
\hline
\end{tabular}

\subsection{Investigation on Pod Traits of Peanuts Under Different Intercropping Models}

As shown in Table 5, the number of mature pods on single plant, the number of single and double kernel pods, the weight of a hundred pods, the weight of a hundred kernels, the kernel rate, and the single plant yield of intercropped peanuts with mulching film were all higher than those figures under the same conditions without the film. The number of blighted pods of intercropped peanuts with mulching film was also slightly lower than without. In the cases both with and without mulching film, all pod trait indicators except for the number of blighted pods were higher for peanuts planted $15 \mathrm{~d}$ ahead of the cassava than for simultaneous planting. In particular, the number of mature pods on single plant, the weight of a hundred pods, the weight of a hundred kernels, the kernel rate, 
and the single plant yield of peanuts planted $15 \mathrm{~d}$ ahead with mulching film were $127.3 \%, 31.4 \%, 29.6 \%, 12.1 \%$ and $49.6 \%$ higher than those of conventional planting (planting at the same time, without mulching film) respectively; the number of blighted pods was $50.0 \%$ lower than that with conventional planting. The results show that intercropping peanuts with mulching film increased the number of pods and pod plumpness, reducing the number of blighted pods, thereby increasing yields.

In the tests on row spacing arrangement, the number of mature pods on single plant, the number of single kernel pods, and that of blighted pods, and the kernel rate of one row of cassava intercropped with four rows of peanuts with a wide spacing $(1.5 \mathrm{~m})$ were all higher than those indicators for one row of cassava intercropped with two rows of peanuts with row spaced $0.9-1.3 \mathrm{~m}$. The number of double kernel pods, the weight of a hundred pods, and the weight of a hundred kernels of one row of cassava intercropped with two rows of peanuts were higher than for one row of cassava intercropped with three or four rows of peanuts. In particular, the single plant yield was the largest when intercropping two rows of peanuts with medium cassava row spacing $(1.1 \mathrm{~m}), 24.3 \%$ higher than that from one row of cassava intercropped with two rows of peanuts with narrow spacing $(0.9 \mathrm{~m})$, and $26.7 \%$ higher than that from one row of cassava intercropped with four rows of peanuts with wide spacing $(1.5 \mathrm{~m})$.

Table 5. Effects of Cassava/Peanut Intercropping Model on Peanut Pod Traits.

\begin{tabular}{|c|c|c|c|c|c|}
\hline Intercropping model & & $\begin{array}{l}\text { Number of mature pods } \\
\text { on single plant (count) }\end{array}$ & $\begin{array}{l}\text { Number of single } \\
\text { kernel pods (count) }\end{array}$ & $\begin{array}{l}\text { Number of double } \\
\text { kernel pods (count) }\end{array}$ & $\begin{array}{l}\text { Number of blighted } \\
\text { pods (count) }\end{array}$ \\
\hline \multirow{3}{*}{$\begin{array}{l}\text { Sowing gap period(d) and } \\
\text { application of mulching } \\
\text { film }\end{array}$} & $0 \mathrm{~d}$ & 7.7 & 0.7 & 7.0 & 3.0 \\
\hline & $15 \mathrm{~d}$ & 10.5 & 1.2 & 9.3 & 1.9 \\
\hline & $\mathrm{m} 15 \mathrm{~d}$ & 17.5 & 3.1 & 14.4 & 1.5 \\
\hline \multirow{3}{*}{$\begin{array}{l}\text { Row spacing of cassava } \\
\text { (rows of peanut) }\end{array}$} & $0.9(2)$ & 9.8 & 2.0 & 7.8 & 1.4 \\
\hline & $1.1(2)$ & 10.1 & 1.4 & 8.7 & 1.4 \\
\hline & $1.5(4)$ & 10.6 & 2.9 & 7.7 & 2.5 \\
\hline
\end{tabular}

Table 5. Continued.

\begin{tabular}{|c|c|c|c|c|c|}
\hline Intercropping model & & $\begin{array}{l}\text { Weight of a hundred } \\
\operatorname{pods}(g)\end{array}$ & $\begin{array}{l}\text { Weight of a hundred } \\
\text { kernels (g) }\end{array}$ & Kernel rate (\%) & Single plant yield (g) \\
\hline \multirow{4}{*}{$\begin{array}{l}\text { Sowing gap period(d) and } \\
\text { application of mulching } \\
\text { film }\end{array}$} & $0 \mathrm{~d}$ & 140 & 54 & 65.5 & 15.0 \\
\hline & $15 \mathrm{~d}$ & 146 & 65 & 68.5 & 22.3 \\
\hline & $\mathrm{m} 0 \mathrm{~d}$ & 145 & 58 & 72.1 & 16.5 \\
\hline & $\mathrm{m} 15 \mathrm{~d}$ & 184 & 70 & 73.4 & 22.4 \\
\hline \multirow{3}{*}{$\begin{array}{l}\text { Row spacing of cassava } \\
\text { (rows of peanut) }\end{array}$} & $0.9(2)$ & 131 & 47 & 64.9 & 10.7 \\
\hline & $1.1(2)$ & 130 & 48 & 64.6 & 13.3 \\
\hline & $1.5(4)$ & 113 & 41 & 63.2 & 10.5 \\
\hline
\end{tabular}

\subsection{Analysis of the Yields of Cassava and Peanuts Under Different Intercropping Models}

As shown in Table 6, in the tests on film mulching and sowing time gap, the peanut and cassava yields, and the intercropping income using mulching film were all higher than those without the film; the peanut yields of the models planting peanuts $15 \mathrm{~d}$ ahead of the cassava were all higher than those of the models using simultaneous planting. The cassava yields of models with a time gap of $15 \mathrm{~d}$ were slightly lower than those of the models planted at the same time. The total income from both cassava and peanuts with a sowing gap of $15 \mathrm{~d}$ was higher than that of the models planted at the same time, among which the income of the model with mulching film was the highest, $18.7 \%$ higher than without.
In the tests on intercropping row spacing, the peanut yield was the highest from one row of cassava intercropped with four rows of peanuts with a wide spacing $(1.5 \mathrm{~m})$, while the cassava yield under this model was the lowest. The income from this model was the lowest among the four. The cassava yield was relatively high with one row of cassava intercropped with two rows of peanuts, with a medium-narrow row spacing $(0.9 \mathrm{~m}-1.1 \mathrm{~m})$. The incomes from one row of cassava intercropped with two rows of peanuts, with row spaced at $0.9 \mathrm{~m}$ and $1.1 \mathrm{~m}$, were respectively $8.0 \%$ and $5.3 \%$ higher than that of one row of cassava intercropped with three rows of peanuts, with row spacing of $1.3 \mathrm{~m}$. This result indicates that spacing cassava rows too far apart reduced the planting density of the cassava, thereby affecting its yield.

Table 6. Effects of cassava/peanut intercropping model on the yields of cassava and peanuts.

\begin{tabular}{|c|c|c|c|c|}
\hline \multirow{2}{*}{ Intercropping model } & & \multicolumn{2}{|c|}{ Average yield $\left(\mathrm{kg} / \mathrm{hm}^{2}\right)$} & \multirow{2}{*}{$\begin{array}{l}\text { Total intercropping income } \\
\left(\text { yuan } / \mathbf{h m}^{2}\right)\end{array}$} \\
\hline & & Peanuts & Cassava & \\
\hline \multirow{4}{*}{$\begin{array}{l}\text { Sowing gap period }(\mathrm{d}) \text { and } \\
\text { application of mulching film }\end{array}$} & $0 \mathrm{~d}$ & 1979.2 & 40879.5 & 38641.5 \\
\hline & $15 \mathrm{~d}$ & 2229.2 & 37968.0 & 37669.5 \\
\hline & $\mathrm{mod}$ & 2032.4 & 43131.0 & 42072.0 \\
\hline & $\mathrm{m} 15 \mathrm{~d}$ & 2680.6 & 42384.0 & 45852.0 \\
\hline Cassava row spacing (rows of & $0.9(2)$ & 2510.8 & 44037.0 & 45117.9 \\
\hline
\end{tabular}




\begin{tabular}{lllll}
\hline \multirow{2}{*}{$\begin{array}{l}\text { Intercropping model } \\
\text { peanuts) }\end{array}$} & \multicolumn{2}{c}{ Average yield $\mathbf{( k g / \mathbf { h m } ^ { 2 } )}$} & \multicolumn{1}{c}{$\begin{array}{l}\text { Total intercropping income } \\
\left(\mathbf{y u a n} / \mathbf{h m}^{2}\right)\end{array}$} \\
\cline { 2 - 4 } & & Peanuts & Cassava & 44002.2 \\
& $1.1(2)$ & 2425.5 & 43375.5 & 41757.0 \\
& $1.3(3)$ & 2591.9 & 35823.0 & 38098.6 \\
\hline
\end{tabular}

\section{Discussion}

\subsection{Selection of Peanut Varieties Suitable for Intercropping with Cassava}

The selection of peanut varieties with shade tolerance to intercrop with cassava was one of the important factors for increasing yield. The 3-year selection tests on peanut varieties, carried out under the field condition of natural shade, showed that the average yield of Guihua 771 was the highest among all tested peanut varieties, and its yield performance in different years was also the most stable, showing that it is the most suitable for intercropping. This result is consistent with the preliminary selection results in earlier studies [16], and it supplements and verifies the earlier results. Guihua 771 had a medium plant height, relatively short length of lateral branch, more effective branch, and fewer main stem nodes, indicating that the plant type was concentrated, the lodging was good, there were more main stems, and the shorter lateral branch could reduce shading by the cassava. These plant traits may be important indicators of the good shade tolerance of Guihua 771 and its suitability for intercropping. In addition, Guihua 771 had the largest number of double kernel pods on a single plant, and the weight of a hundred of its pods, kernel rate, and single plant yield were also the largest among all of the tested varieties. These pod traits were the key factors intercropping yield. Thus, the peanut varieties with medium plant height, short lateral branch, more effective branch, concentrated plant type, more pods on a single plant, and higher kernel rate are suitable for intercropping with cassava.

\subsection{Investigation on Efficient Cassava/Peanut Intercropping Cultivation Models}

Finding a reasonable and efficient cultivation model for cassava/peanut intercropping is very important for balancing the growth of the two plants, improving the utilization of land resources, and increasing income for farmers. In this study, the comprehensive economic benefits of different intercropping modes were analyzed through tests on film mulching, sowing time gap, and different row spacing arrangements. The results showed that the income was the highest from one row of cassava intercropped with two rows of peanuts, with a medium-narrow row spacing. In this way, the cassava intercropped with the peanuts at its original planting density, not only ensuring that its yield was not greatly affected, but also adding the peanut yield. However, if the row spacing of cassava was too wide, its planting density decreased, affecting its yield, and reducing the total economic benefit. In the tests on film mulching and sowing time gap, the economic benefit was the highest from planting the peanuts $15 \mathrm{~d}$ ahead of the cassava, with mulching film, perhaps because the mulching film could effectively preserve heat and moisture, increasing the accumulated temperature of the peanuts, and making intercropped peanuts with mulching film mature earlier than those exposed to the air. Doing so reduced the symbiotic period of the intercropping, and the shading time by the cassava. Moreover, planting the peanuts $15 \mathrm{~d}$ ahead of the cassava increased its growth speed. The closing period of cassava was $15 \mathrm{~d}$ later than that from planting at the same time, avoiding the key period of peanut plumpness, and the vigorous growth period of the cassava reduced shading during the peanuts' key growth period (pod maturity period), thus increasing pod plumpness, and improving its yield and economic benefit.

\section{Conclusion}

The high efficiency cultivation of cassava/peanut intercropping were selecting Guihua771 as peanut variety intercroping with cassava, and using the row spacing of one row cassava intercropping with two row peanut (the row spacing of cassava was $0.9 \mathrm{~m}-1.1 \mathrm{~m})$, and sowing peanut early $15 \mathrm{~d}$ than cassava, and mulching film.

\section{Acknowledgements}

We would like to thank the National Natural Science Foundation Project (31401318 \& 31660371), the Earmarked Fund for China Agriculture Research System (CARS-13-Southern China), Guangxi Natural Science Foundation Project (2017GXNSFAA198144) and Scientific Project from the Guangxi Academy of Agricultural Sciences (2015JZ12 \&2017JZ12) for financial support.

\section{References}

[1] Wei B H, Ruan J Z, Gan X Q, Luo SF. A study testing high yield and efficient cassava cultivation models. China Tropical Agriculture, 2009, 5, 42-43.

[2] Yuan Z Q, XiaoY P, Liu R G, Wang R Q. The efficient planting of intercropped cassava on red dry sloping soil. China Tropical Agriculture. 2008, 5, 63-63.

[3] Luo X L. A study on yield effects and eco-economic benefits of cassava and peanut intercropping. Tillage and Cultivation, 1998, 4, 1-3.

[4] Huang Q R, Sun Y M, Xiong C G, et al. An analysis of the yield benefit from intercropping peanut with cassava on hilly dry red soil. Acta Agriculturae Jiangxi, 2009, 21 (7), 43-45.

[5] Mason S C, Leihner D E and Vorst J J. Cassava-cowpea and cassava-peanut intercropping. I. Yield and land use efficiency. Agron J. 1986a, 78, 43-46. 
[6] Mason S C, Leihner D E and Vorst J J. Cassava-Cowpea and Cassava-Peanut Intercropping. II. Leaf Area Index and Dry Matter Accumulation. Agron J., 1986b, 78(1), 47-53.

[7] Mason S C, Leihner D E and Vorst J J. Cassava-cowpea and cassava - peanut intercropping. III. Nutrient concentration removal. Agron J., 1986 c, 78(3), 441-444.

[8] Polthanee A, Wanapat S and Mangprom P. Row arrangement of peanut in cassava-peanut intercropping: I. Yield, land use efficiency and economic return. Khon Kaen Agric. J. 1998, 26 (2), 85-91.

[9] Polthanee A, Wanapat S and Mangprom P. Row arrangement of peanut in cassava-peanut intercropping: II. Nutrient removal and nutrient balance in soil [J]. Khon Kaen Agric. J. 1998, 26 (3), 125-131.

[10] Kotchasatit A. Growth, yield and nutrient uptake of cassava and peanut in cassava/peanut intercropping systems under rained conditions at Khon Kaen Province. M. S Thesis, Faculty of Agriculture, Khon Kaen University, 1999.

[11] Tang X M, Zhong R C, Jiang J, et al. The effect of cassava/peanut intercropping on microecology in rhizosphere soil. Genomics \& Applied Biology, 2015, 117-124.
[12] Xu H Q, Huang J, Liu Z F, et al. Effects of cassava-peanut intercropping on microbial amount, community structure and diversity in rhizosphere soils. Journal of Southern Agriculture, 2016, 47(2):185-190.

[13] Chen X, Tian Y, Guo X F, et al. The effect of monoculture peanut and cassava/peanut intercropping on physical and chemical properties in peanut rhizosphere soil under the biochar application and straw mulching. IOP Conference Series: Earth and Environmental Science. IOP Conference Series: Earth and Environmental Science, 2017， 59, 012021.

[14] Tang X M, Zhong R C, Jie H K, et al. Effect of cassava-peanut Intercropping on metabolites and key enzyme activity of carbon-nitrogen metabolism of peanut leaf. Southwest China Journal of Agricultural Sciences, 2014, 6, 2316-2321.

[15] Zeng L, Zhou F, Chen Y, et al. Effects of cassava-peanut Intercropping on the absorption of cadmium and available nutrient in rhizosphere soil. Research of Environmental Sciences, 2018, 2, 303-309.

[16] Jie H K, Jiang J, Tang X M, et al. A preliminary report on selection tests on peanut varieties suitable for cassava Intercropping. Journal of Southern Agriculture, 2011, 42 (1), $30-32$. 